\title{
O SUJEITO CEREBRAL ${ }^{1}$ THE CEREBRAL SUBJECT
}

\author{
Alain Ehrenberg* \\ Tradução de Marianna T. de Oliveira \& Monah Winograd
}

Gary [...] tinha cada vez mais dificuldade de acreditar que seu problema não era neuroquímico, mas pessoal.

(Franzen, 2002)

Erik R. Kandel (1999), que recebeu em 2000 o Prêmio Nobel de Fisiologia e de Medicina por seus trabalhos sobre a memória dita procedimental, acredita que a maioria dos biólogos está convencida de que o espírito será, para a biologia do século XXI, o que o gene foi para a biologia do século XX (Kandel, 1999).

Esta biologia será uma ciência do homem total e seu objetivo está claramente indicado pelo argumento de um colóquio sobre "A biologia da consciência. Neurociências, neuropsiquiatria, cognição", que se realizou em Paris, em abril de 2002, sob a presidência de Gerald Edelman (1992): "As neurociências são a chave dos processos de aprendizagem, dos comportamentos sociais, das disfunções neurológicas e mentais". O social, o cerebral e o mental serão fundidos nesta nova ciência rainha.

As disciplinas hoje reagrupadas sob a etiqueta "neurociências" interessavam-se tradicionalmente pelo movimento, pelos sentidos (visão, audição etc.), pela aprendizagem e pelas doenças neurológicas (Alzheimer, Parkinson). Existia igualmente uma importante tradição de pesquisa em psiquiatria biológica sobre as patologias mentais. A partir dos anos 1980, as neurociências permitiram a produção de duas

* Sociólogo e pesquisador do Centro Edgar-Morin; Diretor do Centro de Pesquisa Psychotropes, Santé Mentale, Société du Centre National de Recherche Scientifique (CNRS) - França. 
mudanças. Por um lado, as doenças neurológicas e as doenças mentais se tornaram suscetíveis de serem abordadas como uma única espécie de doença. Por outro, o perímetro de ação dessas disciplinas se estendeu às emoções, aos comportamentos sociais e aos sentimentos morais. Graças à imageria cerebral e às novas técnicas de biologia molecular que permitem "ver o cérebro em ação", poder-se-ia não somente esperar progressos no tratamento das patologias mentais, mas, ainda, anunciar o surgimento de uma biologia da consciência ou do espírito. Saídas do gueto da especulação metafísica, estas noções são doravante objeto de numerosas experiências de laboratório. Human Brain Projects foram elaborados nos Estados Unidos e na Europa segundo o mesmo modelo do genoma humano, com vistas a estabelecer vários atlas do cérebro, conservados em bancos de dados (Beaulieu, 2001). Nas revistas científicas de mais prestígio e na mídia, são anunciados regularmente resultados sobre os circuitos neuronais da simpatia e do luto, da decisão de compra, da crença em Deus, da violência, do amor, etc ${ }^{2}$. Um relatório da Academia de Ciências, por exemplo, sublinha que apreender o cérebro é indispensável a fim de compreendermos a nós mesmos (Korn, 2003). Esta ideia é igualmente comum entre os psicólogos cognitivistas que "redescobrem" o cérebro como objeto da psicologia.

Estes empreendimentos constituem um dos aspectos das guerras do sujeito evocadas na apresentação desse dossiê. Se a tensão entre uma concepção do homem como ser corporal e cerebral e uma concepção adversa do homem como ser social e falante é tradicional em psiquiatria ${ }^{3}$, um novo contexto instalou-se: o sofrimento psíquico e a saúde mental tornaram-se os principais pontos de referência da individualização da condição humana dentro da sociedade da autonomia generalizada. Eles oferecem uma nova linguagem que permite expressar as tensões sociais que acompanham este regime normativo ${ }^{4}$. $\mathrm{O}$ contexto aviva as polêmicas, pois a clientela potencial concerne a cada um de nós. As neurociências são o aporte científico, tecnológico e médico que permite responder à fabulosa demanda de saúde mental que se difundiu há 20 anos nas nossas sociedades.

Minha proposta é menos tomar partido na guerra entre partidários do "Sujeito cerebral" e do "Sujeito falante" do que deslocar seus termos, utilizando a filosofia das ciências como ponto de apoio para uma antropologia do individualismo. A patologia mental é um bom terreno para clarear a confusa questão do indivíduo, pois ela apresenta o grande interesse de ser o domínio onde a dupla constituição biológica e social da espécie humana, dupla constituição que condiciona a possibilidade de nossa vida psíquica, se mistura inextricavelmente.

Para clarear o debate sobre o cérebro em psiquiatria e na vida social, proponho um procedimento de análise das neurociências que distingue dois programas e três perspectivas. 
Pode-se, com efeito, distinguir um programa "fraco" e um programa "forte" de neurociências. O programa "fraco" visa o progresso no tratamento das doenças neurológicas (Parkinson, Alzheimer) e a descoberta dos aspectos neuropatológicos das doenças mentais, como as esquizofrenias. O programa "forte", ao qual darei atenção aqui, identifica, filosoficamente falando, conhecimento do cérebro e conhecimento de si mesmo e, no plano clínico, acredita poder fundir neurologia e psiquiatria, quer dizer, in fine, tratar as psicopatologias neuropatologicamente e, talvez num prazo mais longo, agir mais eficazmente sobre nossa maquinaria cerebral para aumentar nossas capacidades de decisão e ação. Tal versão maximalista visa construir uma biologia do espírito, "uma neurobiologia da personalidade", dito de outro modo, uma biologia do indivíduo. Se uma tal biologia é cientificamente desejada, que tipo de individuo será seu alvo? Responder a esta questão esquecida pelos dois campos permitirá, talvez, decidir entre hipóteses cientificas ambiciosas suscetíveis de recaídas médicas e o bla-bla-blá metafísico.

O programa forte das neurociências evidencia três perspectivas: teórica, prática e social. A perspectiva teórica é a explicação do espírito sobre uma base exclusivamente materialista a partir do postulado de que o cérebro é o "fundamento" do espírito. Esta perspectiva não é nova, mas o contexto de progresso científico e de intensa preocupação com o sofrimento psíquico e com a saúde mental faz dela, hoje em dia, uma perspectiva prática (profissional e terapêutica): a aproximação, através da fusão, entre neurologia e psiquiatria, cuja separação teve início no final do século XIX, estará em breve ao alcance das mãos. Nos últimos anos, os apelos pela fusão das duas profissões são objeto de numerosos artigos nas revistas que dão o tom da pesquisa e elaboram as referências em matéria de tratamento nos hospitais universitários. Aliás, numerosos resumos apresentam o estado da arte, colocando no mesmo conceito de "doença" o Alzheimer e as esquizofrenias5. O que significa que poderíamos, ao final, tratar as patologias psiquiátricas como problemas neurológicos. A perspectiva social se situa, ao mesmo tempo, nestas questôes terapêuticas e além delas: em que medida a referência ao cérebro para descrever e compreender os comportamentos sociais é suscetível de entrar na linguagem comum? O cérebro pode ser - e em que condições - um objeto de identificação, um meio de se reconhecer como um agente social? Este órgão não pode ser mais considerado hoje somente como um objeto científico e médico, ele foi promovido também a ator social. A opinião publica está em vias de adotar a ideia de que nossas dificuldades relacionais e psicológicas não são pessoais, mas neuroquímicas? Trata-se de uma metáfora? De uma vã proclamação à qual nin- 
guém adere verdadeiramente? De uma nova linguagem para justificar nossos atos, suscetível de se difundir socialmente? É o que se deve explorar.

De saída, afirmemos que a redefinição em curso das fronteiras entre neurologia e psiquiatria não porá fim à tensão entre o sujeito cerebral e o sujeito falante, pois essa tensão não é somente interna ao mundo da psiquiatria e da saúde mental, ela é tão inerente à nossa forma de ver que não poderia ser superada. Aqui, uma aproximação antropológica se revela útil.

Se a pesquisa em neurobiologia molecular é evidentemente necessária, eu gostaria de mostrar que o programa forte é um subproduto típico de uma de nossas principais crenças individualistas, a saber, que o homem está primeiramente fechado na interioridade de seu corpo, lugar de sua verdade, e que, em seguida, graças ao seu espírito, ele entra em relação com outrem para formar (por contrato, imitação ou obrigação) uma sociedade. Essas crenças não são especificas das neurociências: elas são igualmente muito comuns em sociologia e antropologia. Se as neurociências têm tendência a fetichizar o cérebro, as ciências sociais fazem o mesmo com esta entidade mágica que é o si-mesmo (íntimo, social, objetivo, farmacológico, etc $)^{6}$.

Sintetizarei primeiramente os elementos da grande divisão que, no final do século XIX, separou as doenças da lesão e as doenças da função, grande divisão que o programa forte pretende superar. Em seguida, discutirei a utilização de dois argumentos recorrentes na literatura científica: a existência de uma ponte entre o cérebro e o espírito, a relação entre a especificidade biológica de um indivíduo e a especificidade do mesmo indivíduo como ser social. Terminarei, enfim, com uma interrogação sobre o contexto social que leva a considerar o cérebro como um indivíduo, em outras palavras, a se pensar a si próprio como um cérebro são ou enfermo.

\section{0-2000: NASCIMENTO E DECLÍNIO DA GRANDE DIVISÃO ENTRE NEUROLOGIA E PSICOPATOLOGIA}

A ideia de uma neurobiologia do sujeito humano, ou seja, de um cérebro assimilado a este sujeito, se banalizou, as neurociências tendo aparecido nas mais importantes revistas internacionais como o futuro da psiquiatria, já que elas representam uma contribuição fundamental para a compreensão dos distúrbios mentais (em que consiste exatamente a contribuição para o tratamento das doenças mentais fica a precisar). O objetivo é compreender os mecanismos celulares e moleculares com a esperança de que, a longo prazo, se poderá agir sobre o cérebro para modificar os estados mentais. 
Vários neurocientistas deixam que se espere, por fim, uma explicação completa do espírito pelos mecanismos neurobiológicos ou pelas representaçōes mentais, e isto apesar do fato de que, como sublinham Albright, Jessel, Kandel e Posner (2000) no balanço das neurociências do século XX, publicado em fevereiro de 2000 na prestigiosa revista Cell, "os problemas [são] inacreditavelmente complexos, mais complexos do que qualquer assunto ao qual nós já tenhamos sido confrontados antes em outros domínios da biologia" (Albright e cols., 2000), e ainda, como lembra Edelman (1992) dentre tantos outros, apesar de "que se trata do objeto material mais complexo que conhecemos no universo" (Edelman, 1992).

Nancy Andreasen (2001) (redatora-chefe do American Journal of Psychiatry), numa obra destinada ao grande público, sublinha que:

a convergência desses dois domínios do conhecimento [biologia molecular e neuroimagem] é uma das coisas mais excitantes que estão ocorrendo atualmente em medicina e em saúde mental. Sua convergência já mudou a maneira como nós pensamos, ao mesmo tempo, as causas e o tratamento das doenças mentais (Andreasen, 2001: 9-10).

Progressos no curto prazo são, nos diz ela, esperados relativamente às causas da esquizofrenia, dos transtornos do humor e dos transtornos de ansiedade. A longo prazo, precisa Andreasen (2001), o objetivo é "achar 'uma penicilina da doença mental'. Gostaríamos de combater a esquizofrenia ou a demência tão eficazmente quanto podemos combater as doenças infecciosas" (Andreasen, 2001: 11).

Este programa implica acabar com a grande divisão estabelecida, entre os anos 1880 e a primeira década do século XX, entre as doenças da lesão e as doenças da função. A distinção lesão/função permite estabelecer sobre uma base clínica as fronteiras entre neurologia e psiquiatria. Para compreender os problemas levantados pelo projeto de uma biologia da personalidade, é necessário explicar as razões dessa divisão.

Um nome marca para nós a clínica mental da época: Freud. O peso da psicanálise na psicologia clínica e na psiquiatria, mas também na cultura ocidental do século XX, é tal que esquecemos dos debates que deram origem à psicopatologia e as suas perspectivas ${ }^{7}$.

A histeria foi a patologia que permitiu construir a ideia de psiquismo e lhe dar um conteúdo específico diferente de uma lesão cerebral. Na época, para falar de doença era necessário que houvesse uma lesão explicando o mal. Confrontado aos tremendos problemas da ligação entre uma lesão que não se acha e uma 
sintomatologia desconcertante, o neurologista Charcot emprega a noção de "lesão funcional" ou "dinâmica". Isto lhe permite considerar a histeria como uma patologia autêntica, inserindo-a nas classes bem conhecidas das doenças sine materia e das doenças constitucionais para as quais a patologia experimental era impotente em achar lesōes. Em outras palavras, a ideia de função ou de problema funcional não implica absolutamente qualquer psicologia e menos ainda algo que se poderia chamar de psiquismo. Charcot mostra que o signo discriminante da histérica é sua capacidade de ser sugestionada pela hipnose, a qual produz uma reação fisiológica - e não psicológica, a psicologia sendo um tipo de a-mais da fisiologia. Assim, Charcot salva o estatuto de doença da histeria, abrigando-a solidamente, pelo menos é o que ele crê, no rincão da neurologia. A desqualificação desta concepção, por um lado, dá origem à psicopatologia e, por outro, reduz o perímetro de ação da neurologia. Às doenças imaginárias sucedem as doenças da imaginação (Castel, 1998a), as quais vão ser reservadas às múltiplas psicoterapias inventadas nessa época, como, por exemplo, a psicanálise, que emerge dentre elas.

Essa concepção foi contestada por Bernheim (o grande adversário francês de Charcot), que mostra que qualquer um pode ser hipnotizado, e não somente as histéricas, e que, consequentemente, Charcot se engana ao considerar a histeria como uma questão neurológica e fisiológica. Mas, e aí está o gênio de Bernheim, ainda assim, ele não considera que as histéricas enganam o médico, mas sim que a histeria "deve evidenciar uma outra objetividade diferente daquela da qual os médicos e os fisiologistas fazem uso e com a qual lidam".

Aqui, a função é autonomizada relativamente à lesão. Lida-se com problemas funcionais no sentido atual da expressão, ou seja, sem precisar invocar uma base orgânica para explicar o mal. É esta ruptura que permite pensar em uma outra objetividade: o psiquismo. A isso Bernheim acrescenta ainda algo mais: "Há [sujeitos hipnotizados] que conservam muita vontade para certas coisas, que só cumprem as sugestōes que lhes são agradáveis ou indiferentes”. Em outras palavras, se não se pode sugestionar qualquer coisa a qualquer um, é porque há algo no sujeito que aceita ou recusa, algo de puramente pessoal. Assim, Bernheim faz emergir o próprio de um sujeito, ou seja, a existência do subjetivo ${ }^{8}$.

Ao contrário de Bernheim, o neurologista Babinski, antigo chefe de clínica de Charcot, pensa que é impossível saber se a histérica fantasia ou não. Ele elimina assim a subjetividade, pois ela não tem nada a ver com a neurologia (pode-se reproduzir e eliminar à vontade os sintomas pela sugestão; isto não pode, portanto, ser um problema de lesão) e, consequentemente, com as doenças mentais que pertencem à psiquiatria. Sua contribuição é ter estabelecido uma fronteira entre o neurológico e psicológico, colocando em questão a possibilidade de compreender 
os estados mentais a partir de estados cerebrais. Ora, é precisamente isso o que tenta fazer nosso programa forte contemporâneo. Certamente, ele se situa em oposição a Freud e à psicanálise, os quais apresentam os problemas em termos de relações fantasmáticas (são doenças da imaginação), enquanto que a neurobiologia e a psiquiatria biológica pensam em termos de déficit cognitivo; mas ele se situa igualmente em oposição às concepçôes de Babinski, que eliminava uma subjetividade hoje reintroduzida ${ }^{9}$. Mas em que consiste uma subjetividade doente que não é mais feita de culpabilidade, de ideias obsessivas, de medos irracionais ou de fantasmas torturantes?

Entre a abertura feita por Bernheim e outros psicólogos do fim do século a ideia de psíquico - e o fechamento da neurologia ao inobjetivável, feito por Babinski, Freud dá origem a uma maneira singular de tratar os sujeitos humanos. Ele fornece um certo conteúdo a esta noção de psíquico que está emergindo, ou seja, que toma por objeto a subjetividade. Sua contribuição é a descoberta do "poder mágico das palavras", segundo sua expressão na monografia sobre a afasia de 1891 (Freud, citado por Forrester, 1984). O problema de Freud é distinguir a afasia neurológica da afasia histérica. Enquanto se trata de histeria, ele mostra que certamente algo se passa no corpo, como na afasia neurológica, mas não é um fenômeno do corpo. A razão do sintoma (corporal) é um sistema de pensamento, de palavras do paciente, sistema que lhe é próprio: as palavras são mal colocadas, por isso o sintoma é uma linguagem e não o efeito de uma disfunção do sistema nervoso. Mas qual linguagem? O sintoma é uma expressão de tensões entre ideias, das quais o paciente não se dá conta, que funcionam como um sistema de forças e contraforças. Freud não pensa em termos biológicos: a vida psíquica não repousa sobre uma matéria; ela parece antes com um campo de forças (Leader, 2001). Lembremos que Freud elaborou duas tópicas, dois sistemas de forças, no curso de sua vida (inconsciente/pré-consciente/consciente e depois isso/eu/supereu).

A tensão entre as ideias (as forças) é a própria operação do desejo, que é uma entidade conflituosa. E "a tensão do desejo domina o eu”, escreve Freud no Projeto para uma psicologia cientifica em 1895 (Freud, citado por Leader, 2001: 255). Ela se acha no centro da vida psíquica. Isto o conduziu a fazer do animal humano o sujeito de seu desejo, um ser tomado pelo conflito do desejo. Mostrando que se pode estar doente do próprio desejo, Freud descobre assim "uma chave técnica" para tratar um problema - a histeria - que estava posto para toda a medicina (Castel, 1998b).

O período que vai do fim do século XIX ao início do século XX vê estabelecer-se uma separação, fundada sobre a clínica, entre o homem cerebral da neurologia e o homem falante da psicopatologia. No primeiro caso, o sintoma transcen- 
de o paciente que tem uma doença do sistema nervoso (é o seu cérebro o ponto de imputação da terapêutica), no segundo, o sintoma é inteiramente singular ao paciente que está doente de si mesmo, por assim dizer, de sua intencionalidade (desejo, crença, vontade, etc.). A partir daí, psiquiatras e neurologistas procuraram permanentemente as relações entre seus dois domínios. Paralelamente, a distinção entre lesão e função se tornou o nó das controvérsias sobre as relações corpoespírito (ou cérebro-espírito).

Seriam as neurociências a denominação de uma nova neurologia, cujo programa seria muito mais ambicioso do que o de Babinski, uma vez que cruzaria a fronteira entre estar doente do cérebro e estar psicologicamente doente? Esta ambição, a qual os partidários da biologia do espírito pensam resultar do progresso científico, não seria favorecida por um contexto que coloca no centro da vida social a "subjetividade" dos indivíduos, o sofrimento psíquico que eles testemunham? Em que medida as maneiras de pensar o progresso científico e os sentidos dados à vida social misturam-se? Para responder, é necessário trabalhar, ao mesmo tempo, sobre os conceitos e sobre os contextos.

\section{EXISTE UMA PONTE ENTRE O CÉREBRO E O ESPÍRITO?}

Se não é necessário misturar os negócios do filósofo com os do sábio, nessa matéria, o dito sábio faz-se filósofo: ele fala do erro de Descartes (Damásio, 1995), ele pensa que o homem é neuronal (Changeux), ou que se pode explicar o social a partir do cérebro (Edelman, 1992), teses eminentemente filosóficas, mais do que hipóteses científicas. Lembremos que os biólogos, em função de seu ofício, devem trabalhar sobre os seres humanos abordando-os a partir de seus corpos, quer dizer, em neurobiologia, a partir de seu cérebro. Em biologia, o humano é um ser segundo o corpo, um ser que deve metodologicamente ser reduzido ao seu corpo (genes, aminoácidos, enzimas, áreas cerebrais, redes neuronais, neurotransmissores, sinapses etc.). Os biólogos devem neutralizar, por rigor metodológico, o social. $\mathrm{Na}$ falta de uma tal neutralização, não é possível testar experimentalmente as hipóteses ou estabelecer correlações estatísticas.

Por isso, é surpreendente que numerosas especulaçôes biológicas sobre o espírito efetuem um passo a mais que, na minha concepção, é um passo demais. Precisemos: um passo que pula da necessária neutralização metodológica do social à cegueira conceitual; o ser abordado segundo o corpo sendo frequentemente assimilado, implícita ou explicitamente, ao ser considerado em sua totalidade. $\mathrm{O}$ passo demais é um erro, ao mesmo tempo lógico e antropológico, que remete à questão das relações entre o sujeito humano e seu corpo, entre o todo e a parte. 


\section{DisTINGUIR CAUSAS E RAZŌES}

Como o cérebro produz o espírito ou os estados mentais (ansiedade, delírio, memória, cognição etc.)? Na literatura científica, tem-se a tendência a responder pela hipótese de uma "ponte" entre o cérebro e o espírito, entre os mecanismos moleculares e os estados mentais. Poderemos descobrir ou construir esta ponte graças ao progresso da biologia molecular e da imageria cerebral ${ }^{10}$. As extremas dificuldades não são de maneira alguma negadas, mas os pesquisadores pensam resolvê-las considerando que as patologias do espírito devem ser abordadas segundo o modelo das doenças somáticas ditas complexas, como o câncer e o diabetes, cujas causas são multifatoriais. As lesões do cérebro são, então, os verdadeiros atores da patologia mental e, de uma maneira mais geral, a experiência pessoal derivaria dos processos bioquímicos no nível molecular.

O problema conceitual que a biologia coloca, que faz dos (complexos) mecanismos cerebrais o sujeito da pessoa, o ator das operaçôes mentais - aquele que age em última instância -, é a confusão entre duas espécies de fenômenos. François Jacob (2000) (que não é neurobiólogo) concluiu seu último livro sobre essa questão: "Nós somos uma perigosa mistura de ácidos nucleicos e de lembranças, de desejos e de proteínas. O século que termina se ocupou muito dos ácidos nucleicos e das proteínas. O seguinte vai se concentrar nas lembranças e nos desejos. Será que ele vai saber resolver tais questôes?” (Jacob, 2000: 220).

Daí uma questão: somos compostos no mesmo sentido de proteínas e de desejos? Tal formulação corresponde à natureza dos fenômenos estudados? Se não é esse o caso, não seria necessário distinguir as duas espécies de fenômenos? E segundo quais critérios?

Uma distinção, introduzida por Wittgenstein, entre causas e razões nos ajudará. A formação de uma proteína é o objeto de uma hipótese verificável pelo fato de que, se descobrimos uma causa para a proteína x, essa causa, nas mesmas condições, agirá necessariamente para formar sempre a mencionada proteína: lidamos com a expressão de uma regularidade natural, constatável empiricamente e previsível (se temos tal causa, teremos, de modo mecânico ou probabilístico, tal efeito). A relação causal se caracteriza, então, pela exterioridade da causa e do efeito, que são dois acontecimentos independentes um em relação ao outro. Consequentemente, uma causa não tem autor. Uma razão ou um motivo, ao contrário, têm um autor e não se pode separar o autor de suas razões, ao contrário da causa e do efeito: sou eu que me lembro ou que não desejo. Uma razão é essencialmente uma interpretação das nossas açôes, ela não é imposta pelos fatos: "Eu não me lembro mais porque" não reenvia principalmente a uma causa, mas a uma 
razão, uma justificativa. A razão é o que torna uma ação inteligível, o que lhe dá um sentido - ser ela mentirosa, verdadeira ou errônea não é o problema. O desejo e a lembrança são, com efeito, providos de intencionalidade (como crer, querer etc.), o que significa que eles são orientados em direção a um objeto (eu quero que a chuva caia) e não em direção a um fato (a chuva cai). Dito de outro modo, eles são regulados pela linguagem: eu invoco um desejo ou uma ausência de lembrança para justificar minha ação (eu fiquei assim em razão de ter me tornado sociólogo ou ter perdido um encontro) e em função do que é aceitável a este título pelo outro, o que supõe um mundo, uma relação entre mim e ele, logo, um contexto, ou seja, uma vida social. Em contrapartida, invoco meu desequilíbrio de ácido úrico ou minha tendinite crônica nos joelhos para explicar que eu caí ou que eu manco e em função do que se passa realmente.

A solução que não distingue as espécies e não as hierarquiza em níveis se refere a: "resolver o problema psicofísico substituindo a alma etérea e insaciável do filósofo pela alma material e tangível do sábio, a saber, o cérebro" (Bouveresse, [1976] 1987: 677).

A existência de alterações cerebrais não é um argumento: na medida em que possuímos um corpo, é normal que múltiplas intermediações biológicas (neurotransmissores, sinapses, artérias cerebrais etc.) nos façam sentir o que nós sentimos. Aqui, a distinção das causas e das razões deve ser considerada como hierárquica: a mecânica causal do cérebro é englobada no universo das significações do qual ela deriva. As significações implicam a preeminência dos valores (bem/mal, bonito/feio) e regras (permitir, ordenar, proibir) sobre o corpo (ou o cérebro).

\section{INDIVIDUAÇÃO E INDIVIDUALIZAÇÃO}

A espécie humana é geneticamente equipada para uma diferenciação infinita de indivíduos. Assim, cada cérebro é específico a cada ser humano, inclusive o dos gêmeos monozigóticos. Mas a identidade biológica seria a identidade de uma pessoa considerada em sua totalidade? "Pensem", escreve Antonio Damásio, "naquilo que poderia ter dito o príncipe Hamlet, se ele tivesse podido contemplar [na imageria cerebral] suas próprias três libras de cérebro agitadas por pensamentos confusos, ao invés do crânio vazio que lhe estendeu o coveiro" (Damásio, 1995: 47).

Nada de mais? É desejável individuar Hamlet pelo seu cérebro, como podemos fazer com suas impressões digitais. Obteremos, assim, sua impressão cerebral, mas ela nos servirá, sobretudo, para dizer: "é Hamlet", para designá-lo pelo seu cérebro. A identidade biológica é uma individuação. 
Poder-se-ia, eventualmente, ver que Hamlet é ciumento, mas não se poderia dizer de quem ou por que ele tem ciúmes, pois seria necessário que ele no-lo dissesse e no-lo contasse. Há, talvez, uma mediação biológica do ciúme no nível molecular, mas a rede neuronal, o mecanismo cerebral, só poderia ser desencadeado se o sujeito tivesse razóes para ter ciúmes e para estar com ciúmes de alguém com quem ele tem uma relação, em um contexto que lhe dá razões (boas, más, falsas, ilusórias) para tanto. O ciúme é sentido por mim porque estou numa relação significante com alguém. O objeto do ciúme e o ciumento formam um par, são relativos um ao outro em referência ao ciúme. Pode-se separar o ciúme do ciumento ou o luto do enlutado? Sentirei a mesma coisa pela morte de minha mulher independentemente do fato de amá-la ou de não amá-la mais? O sujeito e o objeto (do ciúme e do luto) não são duas entidades independentes às quais adicionamos, depois, uma relação social ou mental: eles são dois agentes. Aqui, não estamos mais na designação individuante, mas na individualização, numa relação significante ${ }^{11}$.

O uso de uma perspectiva exclusivamente naturalista consiste seja em colocar no mesmo plano o ser considerado a partir de seu corpo (neste caso, o cérebro) e o ser considerado como um ser pensante e atuante, seja em fazer do segundo a consequência do primeiro. A confusão entre a individuação e a individualização leva a pensar que o cérebro é, ao mesmo tempo, o sujeito que dirige a pessoa e a pessoa inteira (o que não é o cérebro não conta verdadeiramente). Acredita-se ter, enfim, corrigido "o erro (dualista) de Descartes" e só se faz prolongá-lo com métodos científicos. Em outras palavras, faz-se do cérebro uma alma material.

É necessário, então, manter uma distinção entre a individuação no seio da espécie, ou seja, a identidade pessoal que faz com que uma coisa seja ela mesma (uma mosca ou um homem), e a individualização, o sentido que atribuímos a essa identidade, a consciência que se tem dela. Ora, este sentido não reside no cérebro (que só conhece mecanismos), mas na vida social. Se o programa forte pode produzir, ao final, uma biologia do indivíduo, será uma biologia da individuação e não da individualização.

\section{SuJEITO CEREBRAL E SUJEITO FALANTE: RELATIVIZAR A OPOSIÇÃO}

As especulações, cuja análise acabo de esboçar, têm perspectivas práticas: elas fornecem as referências científicas que permitem prever a integração da psiquiatria e da neurologia. Observa-se, hoje, uma tendência muito forte, nas publicaçôes científicas de renome, a enaltecer tal integração. Em vários artigos, psiquia- 
tras afirmam que "é cada vez mais difícil distinguir cientificamente as disciplinas da neurologia e da psiquiatria" (Martin, 2002: 695) ${ }^{12}$ ou que "chegou a hora de a psiquiatria e a neurologia se tornarem uma única disciplina” (Detre \& McDonald, 1997: 203).

É no plano da clínica que as coisas se passarão: as pesquisas em neurociências permitirão ao programa forte atingir seus objetivos? No caso da psiquiatria genética, vê-se claramente que não é possível, hoje, distinguir verdadeiramente a parte dos genes da parte do meio, sejam quais forem os métodos empregados. Mais ainda, os obstáculos metodológicos são tais que a informação demonstrada corre o risco de ser das mais insignificantes ${ }^{13}$. No nível dos resultados práticos, quais mecanismos fisiopatológicos ou quais marcadores biológicos de uma afecção mental qualquer (permitindo dizer: “eis o mecanismo!”) podem ganhar crédito por todas essas pesquisas? Os resultados referem-se às síndromes de caráter biológico no autismo (cerca de 15\% dos casos).

No plano prático, há pelo menos dois argumentos contra o programa forte. O primeiro diz respeito ao diagnóstico. Tomemos a maneira pela qual é apresentado o autismo num programa de televisão para o grande público. No programa Ça se discute, apresentado por Jean-Luc Delarue e dedicado ao autismo em 13 de outubro de 2003, tanto os pais presentes como a pedopsiquiatra declaram unissonamente que os pais nunca estão em questão, pois se trata de um problema de neurodesenvolvimento, certamente de natureza genética e, em todo caso, constitucional. As propostas sustentadas correspondem perfeitamente às tendências dos profissionais de pesquisa: somente os franceses falariam ainda de psicose infantil, em todos os outros lugares o autismo é um "problema invasivo do desenvolvimento" ${ }^{14}$. No entanto, a clínica mostra que relações patogênicas ${ }^{15}$ durante a primeira infância podem produzir o mesmo tipo de sintoma, ainda que seja frequentemente difícil diferenciar um problema neurológico e biológico de uma doença mental. Essa dificuldade está na origem das intensas controvérsias neste domínio: depois da explicação geral pela "mãe esquizofrênica”, instala-se uma outra explicação geral pelas causas biológicas e pelos déficits cognitivos. Em consequência, o acento posto sobre as causas biológicas impede que se faça um diagnóstico diferencial que conduza a cuidados terapêuticos diversificados e personalizados, segundo a dinâmica daquela sintomatologia específica - uma relação patogênica não significa uma ação intencional por parte dos pais. Essa diferenciação diagnóstica é tão importante de ser estabelecida que um relatório, publicado em 2001 por um órgão americano, o National Research Council, estimou ser impossível depreender, tanto das pesquisas em ciências cognitivas, quanto daquelas 
do domínio florescente do apego, uma conclusão sólida no que diz respeito ao desenvolvimento a longo prazo da criança (Hulbert, 2003).

Distinguir duas espécies de doença permitiria relativizar a oposição entre o cerebral e o relacional. Eles formam as duas partes solidárias do todo que é o paciente.

O segundo argumento é clínico. Em neurologia, os problemas psicopatológicos ou os distúrbios funcionais são suscitados pela causa biológica ou pela própria doença. Esses problemas agravam as dificuldades gerais de pacientes neurológicos e devem ser levados em consideração. Oliver Sacks (1988) é um exemplo de tal perspectiva em neurologia. Ele realmente mostrou a necessidade de uma investigação clinica sutil e de uma profunda compreensão psicológica dos pacientes neurológicos. Em psiquiatria, as neurociências têm um lugar legítimo, pois é razoável pensar que a pesquisa distinguirá mais aspectos neuropatológicos, ou seja, corporais, nas doenças mentais. É uma hipótese razoável porque, por exemplo, o grupo das esquizofrenias é um conjunto de síndromes e é muito possível que assistamos, no final, a um desmembramento da "a" esquizofrenia, com uma parte das síndromes basculando para o domínio da neurologia, como no caso do autismo. No entanto, um retardo no neurodesenvolvimento cria pesados problemas psicopatológicos. Em consequência, ainda quando os pacientes psicóticos se tornarem pacientes neurológicos, a psicopatologia terá o seu lugar. Em outras palavras, por um lado, não se põe fim à divisão entre neurologia e psiquiatria, entre doenças da lesão e doenças da função, e, por outro, não se chega a livrar-se do adjetivo "mental" que mantém sua necessidade. Distinguir o cerebral do relacional, relativizando sua oposição, permite contornar a dupla pegadinha da fusão e da oposição frontal entre neurologia e psicopatologia em proveito do acento posto na clínica e na relação médico-paciente ${ }^{16}$.

Mais que procurar a fusão das duas disciplinas ou, inversamente, pensar que as neurociências colocam em perigo a subjetividade, não será mais racional e eficaz para os pacientes usarem os progressos da biologia do cérebro para melhor refletir sobre a distinção entre as duas disciplinas?

Também é importante sublinhar o interesse de tal desdobramento lógico que começa a se impor pela ideia de que é preciso parar de culpar os pacientes ou seus pais (pelas psicoses e os distúrbios alimentares, anorexia e bulimia), atitude atribuída à psicanálise. Ora, a psicanálise é, a principio, menos feita para culpabilizar pacientes e pais do que para ajudá-los a se confrontarem com suas próprias culpas (sentimento que não é raro numa situação em que se tem uma criança atingida por distúrbios psiquiátricos), o que é outra coisa. Mas, evidentemente, isso não diz nada da prática muito diversa da psicanálise. Livramo-nos de uma subjetivida- 
de passando pela linguagem em proveito de uma subjetividade cerebral. Trata-se de construir uma subjetividade que não designa ninguém em particular, porque ela não leva em conta os conflitos, as divisões, os dilemas nos quais os indivíduos são realmente tomados. É "uma subjetividade do autômato", para retomar a expressão de Vincent Descombes (1995), cujo paradigma é o ser vivo, ou seja, "um ser capaz de se deslocar sozinho, por si mesmo, sem ser impulsionado do exterior" (Descombes, 1995: 218) ${ }^{17}$. Essa subjetividade mínima é, ao mesmo tempo, asseguradora. Ela se difunde e adquire sua legitimidade na socialização do cérebro. Seu uso abusivo não é necessariamente benéfico para os pacientes. Mas pode acontecer o mesmo que aconteceu com a psicanálise: o todo psicanalítico não é uma solução melhor do que o todo biológico. Nenhuma disciplina está protegida da tentação do programa forte.

\section{O VALOR SOCIAL DO CÉREBRO}

Do estresse às esquizofrenias, passando pelos transtornos obsessivo-compulsivos, a depressão ou a dislexia, a midiatização obtida pelas neurociências é indubitável e o cérebro se tornou uma personagem da imaginação contemporânea. Revistas destinadas ao grande público (Psychologie et cerveaux, em 2002), manuais para estudantes de psicologia (Cerveaux et psychologie, em 2002, coleção "Premier cycle", PUF) e guias práticos foram publicados (Como medir suas competências cognitivas? Como controlar suas emoções? Desenvolver o cérebro das crianças? Encontrar as suscetibilidades neurológicas? etc.) (Hulbert, 2003). Numerosas associações de pacientes na França demandam, atualmente, pesquisas em neurociências. As mídias estão falando cada vez mais frequentemente disso e o cérebro é, às vezes, a manchete. Assistimos a uma clara valorização social do conhecimento do cérebro que se junta à literatura sobre a relação (de casal, pais-filhos, patrão-assalariado etc.) no discurso público sobre as patologias mentais e sobre os bons comportamentos a adotar na vida cotidiana.

O programa forte saiu dos laboratórios. Isso significa que uma linguagem naturalista se difunde na vida social. Aliás, ela não está limitada ao cérebro. $\mathrm{O}$ vocabulário psicológico do apego, da resiliência e do traumatismo e aquele das técnicas espiritualistas estão entrelaçados com o da neurologia. Curar o estresse, a ansiedade e a depressão sem medicamentos, nem psicanálise, por David ServanSchreiber (2003), o primeiro grande sucesso popular francês das neurociências, me parece extremamente representativo. Ele propõe sete técnicas que são os elementos de uma "nova medicina das emoções [que] está em vias de nascer um 
pouco em todos os lugares do mundo: uma medicina sem psicanálise, nem Prozac" (Servan-Schreiber, 2003: 21).

Todas essas técnicas fazem apelo ao corpo a partir de um princípio de divisão do cérebro descoberto pelo neurologista Antonio Damásio (1995): o "cérebro emocional", que é "o cérebro do cérebro" e é insensível à cognição e à linguagem. O princípio clínico consiste em reprogramar o cérebro emocional, aumentando suas capacidades, ao que parece bem conhecidas, de autocura. As aptidões que derivam desse princípio "são os fundamentos do domínio de si e do êxito social" (Servan-Schreiber, 2003: 29). O encontro entre certos movimentos espiritualistas, notadamente o budismo, e as ciências cognitivas é uma tendência forte ${ }^{18}$.

\section{UMA RESPOSTA AOS PROBLEMAS PROPOSTOS PELA REGRA DA AUTONOMIA INDIVIDUAL?}

Pode haver crenças irracionais, até mesmo místicas, com respeito à ciência: o contexto situacional comanda os recursos a estas crenças ao lhes dar um valor social. A distinção entre crenças racionais e irracionais é um problema clássico em antropologia: os "primitivos" acreditavam em suas práticas mágicas mesmo que elas não tivessem eficácia (Lara, 2004)? Essa questão sobre as relações deles com a magia deveria ser colocada também para compreendermos nossas relações com as neurociências. Não estou dizendo de forma alguma que a biologia é uma ilusão e tampouco sou partidário do relativismo. Sublinho apenas que a biologia pode "funcionar, na nossa visão de mundo hipercivilizada, um pouco como as forças ocultas da magia antiga" (Bouveresse, 1982: 123-124). Este é o caso, quando uma explicação pelas causas acrescenta pouquíssimo a uma compreensão pelas razões. Em seu livro sobre a feitiçaria dos azandes, Evans-Pritchard ([1937] 1976) mostrou potentemente que a oposição racional/irracional era vazia de sentido e que era necessário relativizar essa oposição, dado que a maioria das pessoas tem uma ideia bastante confusa a respeito desta distinção. A feitiçaria "é uma resposta a certas situações e não um conceito" (Evans-Pritchard, [1937] 1976: 54). Ela não é uma atividade sagrada ao lado de atividades profanas. Ela não é objeto de uma teoria geral. Da mesma forma, a maioria entre nós possui uma ideia vaga daquilo que é científico e daquilo que não o é. Então, é perfeitamente possível se apoiar sobre a biologia em casos para os quais ela não é apropriada. Poderíamos dizer de nossas noções científicas o que Evans-Pritchard sugere de suas noções místicas: elas "são eminentemente coerentes, ligadas por uma rede de vínculos lógicos e tão ordenados que não contradizem tão cruamente a experiência sensorial. Ao contrário, a experiência parece justificá-las" (Evans-Pritchard, [1937] 1976: 150) ${ }^{19}$. 
As razões sociais do sucesso popular das neurociências estão menos relacionadas a seus resultados científicos e práticos do que ao estilo de resposta dada para os problemas formulados pelo nosso ideal de autonomia individual generalizada. Elas permitem, hoje, consolar quem - na realidade, a maioria de nós - tem dificuldade de encarar o mundo de decisão e ação que se edificou sobre as ruínas da sociedade da disciplina, aquela que conhecia o respeito à autoridade cuja perda é objeto de lamentaçôes cotidianas. Mas as neurociências suscitam também a esperança de que sejam dadas a todos técnicas de multiplicação das capacidades cognitivas e de controle emocional, igualmente indispensáveis a tal estilo de vida. É porque as neurociências não são exteriores à ideia de "saúde mental", elas são a sua ponta científica e tecnológica. Os hábitos contraídos com o consumo de medicamentos psicotrópicos, de drogas e substâncias dopantes, essas práticas neuroquímicas de usinagem de si, prepararam o terreno largamente. A extensão das fronteiras de si que a normatividade da autonomia (valorização da realização de si, da ação individual, do self-ownership) recobre faz com que pareçam reunidas as condiçôes para que uma representação de si como cérebro doente constitua uma referência semântica apropriada.

Este já é o caso dos Estados Unidos através das transformações do autismo e da hiperatividade com déficit de atenção no adulto. O critério que torna possível o uso de uma patologia supostamente cerebral é a incapacidade social: este é um dos critérios diagnósticos do autismo e $o$ critério da hiperatividade. $\mathrm{O}$ autismo, tradicionalmente considerado um retardo mental grave ou uma psicose infantil, está conhecendo um alargamento diagnóstico que inclui os casos menos graves, os "Aspergers" (segundo o nome do psiquiatra austríaco que nomeou essa síndrome em 1943 $)^{20}$ : eles possuem um QI normal, mas não têm "teoria do espírito", ou seja, são incapazes de compreender as interaçôes sociais habituais, os subentendidos da linguagem, os signos que nos endereçamos na vida cotidiana e que são supostamente compreendidos por todo mundo. Os autistas de alto-nível, esses "Aspergers", têm frequentemente uma inteligência normal, até mesmo superior, às vezes têm talentos particulares. É a distância entre suas competências intelectuais e suas incompetências sociais que chama atenção. Os Aspies, como eles mesmos se qualificam, são socialmente deficientes, mas não estúpidos ou preguiçosos. Seus déficits não resultam de maus-tratos parentais ou de uma falha no caráter, mas de um cérebro que funciona diferentemente daquele das pessoas normais. Aulas para a aprendizagem de competências sociais começam a entrar em cena nos Estados Unidos e grupos de autoajuda constituem-se onde um número crescente de Aspergers "começam a celebrar sua própria e única maneira de ver o mundo" 21 e clamam por uma tolerância à "neurodiversidade", debochando dos 
"neurotípicos". Uma sumidade mundial sobre a questão, Simon Baron-Cohen (2000), professor em Cambridge, propôs em 2000 uma conferência cuja questãochave consistia em saber se não era finalmente necessário caracterizar os Aspergers menos sob o ângulo de um deficiente do que sob o da diferença de estilo cognitivo.

A síndrome de hiperatividade com déficit de atenção, considerada até agora como uma patologia da infância e da adolescência, atingiria vários adultos desorganizados em seus trabalhos ou incapazes de cumprir uma tarefa corretamente (4\% da população adulta seria atingida no Canadá) ${ }^{22}$. O reconhecimento da síndrome permitiria, graças a uma maior tolerância social, aumentar a estima de si dessas pessoas e assim melhor "assegurar" seu desempenho na vida social. Aí também técnicas de treinamento para a vida social são propostas.

Os disabilities movements promovem uma nova linguagem da incapacidade social, reivindicando a tolerância e o direito à diferença, apoiados sobre a referência ao cérebro. Teríamos ainda podido tomar o exemplo das síndromes neurológicas, como a de Tourette ("a doença dos palavrôes”). Como na versão psicológica, as noções de deficiente e de diferença de estilo de vida são, pelo polo patológico, uma maneira de reformar o tratamento e, pelo polo da normalidade, um estilo de justificativa das dificuldades relacionais nas múltiplas situações da vida cotidiana, em que a questão da responsabilidade pessoal emerge. Elas também são um meio de expressar as tensões da autonomia individual. As versões psicológicas e naturalistas formam as duas partes de um todo: elas dividem um espirito comum.

\section{O CÉREBRO TEM UMA UTILIDADE NA VIDA SOCIAL?}

Mas é necessário perguntar se esse tipo de declaração pode se transformar em uma linguagem aceitável para justificar nossas maneiras de ser e de fazer na vida social. A enquete do antropólogo americano Joseph Dumit (2004) sobre a imageria cerebral e o romance de Jonathan Franzen (2002) dão elementos para resposta.

Joseph Dumit (2004) pensa que, graças à imageria cerebral, um "self-objetivo" está surgindo, "uma categoria ativa de pessoa que se desenvolve através de referências ao saber de experts e é invocada através dos fatos" (Dumit, 2004: 164). Ao fabricarem um self-objetivo, as técnicas de imageria cerebral "ajudam [...] as pessoas sofredoras a negociar com o fato dos sintomas da doença mental” (Dumit, 2004: 166).

Esse fato é a estigmatização social que singulariza as patologias mentais. Dumit (2004) cita um técnico em neuroimagem e psiquiatra clínico: "Uma das mensagens intrínsecas é que a depressão é algo de que é necessário não se ter vergonha. É uma doença que necessita ser compreendida. E não é culpa deles" (Dumit, 2004: 166). 
Encontramos esse tipo de declaração por todos os lados, mas a referência à culpa pessoal e à estigmatização é equivocada. O problema que ela põe é não haver mais critério para distinguir entre a culpa (moral) e a patologia (mental). Ora, para o paciente, essa indistinção tem um preço que é preciso avaliar. Os benefícios produzidos pelo self-objetivo consistem, por exemplo, em poder controlar suas próprias emoçôes sem exercer necessariamente um julgamento severo a respeito de si mesmo.

Mas isso é esquecer que o julgamento severo a respeito de si mesmo é um sintoma e, mesmo, um sintoma característico da depressão, posto que uma de suas principais características é a baixa da autoestima. Quanto ao tema da estigmatização, confundem-se então duas coisas: superar o estigma e superar a patologia.

Superar o estigma tem uma função de segurança. Mas pode aprisionar o paciente em sua doença. Constatamos isso no livro da jornalista Tracy Thompson (1995), que se pergunta continuamente se é a responsável por sua doença e se deve, então, levar a culpa disso, ou se é o seu cérebro. Mas essa lancinante questão jaz sem resposta. Ela perde a batalha contra a vergonha e a culpa. Sua referência ao seu "self-objetivo" só lhe permite a escolha de um estilo de vida deprimido. "Ela forjou para si uma identificação positiva com sua própria doença do cérebro", escreve Dumit (2004: 161), mas é um prêmio de consolação, um benefício secundário porque, onde há patologia, o senso comum permite hoje substituir por um "estilo de vida diferente". Thompson (1995) tenta desesperadamente evitar a culpa e a vergonha - superar o estigma - ao invés de se confrontar com elas, já que são seus sintomas (ideias obsessivas, etc.). A característica dessas patologias é que são patologias "morais". Não danos que afetaram a moral (uma falta), mas patologias cujo sintoma é frequentemente um sentimento moral (culpa delirante na melancolia, escrúpulos inibidores que se exprimem pela vergonha e pela culpa na neurose obsessiva ou na depressão). Foi essa distinção que se perdeu na naturalização e que faz perder de vista o que seja um problema psicopatológico. Claro, pode-se ter vergonha de estar doente de câncer, mas numa neurose obsessiva, ou numa depressão, a vergonha tem um outro estatuto, o de sintoma. Dumit (2004) não faz nada mais que retomar os termos do programa forte sem avaliar seriamente suas possibilidades de utilização social.

O romance de Jonathan Franzen (2002), que teve um grande sucesso comercial e de crítica nos Estados Unidos e na França, traça um retrato justo dos limites do emprego de uma linguagem cerebral na vida social. Ele mostra de que forma isso pode servir para justificar as próprias ações dentro de um contexto (noção, aliás, totalmente esquecida pelo antropólogo Dumit, 2004). Pois o cérebro não 
pode viver a si mesmo (salvo nos casos de distúrbios neurológicos) ${ }^{23}$, e se ele pode se ver na imageria cerebral, ele não tem outra possibilidade senão se dizer dentro da vida social.

O romance põe em cena uma personagem em busca da "Boa Saúde Mental" (Franzen, 2002: 286), que pensa seu mundo relacional apoiando-se sobre uma concepção neuroquímica e cuja preocupação principal é não cair em "depressão clínica":

Outras palavras reconfortantes pareciam necessárias, mas Gary não achou nenhuma delas. Ele sofria um déficit crítico de fatores 1 e 3 . Ele tivera o sentimento, alguns instantes mais cedo, de que Caroline estava no ponto de acusá-lo de estar "deprimido" e ele temia que, se a ideia de que estava deprimido vingasse, perderia todo direito a ter opiniōes. Ele perderia suas certezas morais; cada palavra que pronunciasse se tornaria um sintoma da doença; ele nunca venceria numa discussão (Franzen, 2002: 201).

As variações de humor de Gary são o reflexo de sua vida familiar. Ao contrário de sua mulher, Caroline, ele não encontrou a "Boa Saúde Mental". No mais, ele optou pela neuroquímica, enquanto Caroline escolheu a psicoterapia. Os ingredientes do jogo entre os protagonistas são: "Após seu casamento, ela fez cinco anos de psicoterapia bissemanal até que o terapeuta, na última sessão, declarou que ela obteve 'um sucesso perfeito' e que havia conquistado uma vantagem definitiva sobre o Gary na corrida pela saúde mental” (Franzen, 2002: 199). A guerra doméstica se apresenta da seguinte maneira:

Ele atacava cruelmente sua pessoa [a de Caroline]; ela atacava heroicamente sua doença, a de Gary, doença que ele não quer reconhecer e, sobretudo, na qual ele não quer se deixar aprisionar enquanto indivíduo. Gary resolve uma pequena crise conjugal confessando-se clinicamente deprimido. A confissão ("Eu me rendo") constitui o momento da reconciliação do casal (“Obrigada”, responde Caroline) (Franzen, 2002).

Vê-se em que condiçôes semânticas o discurso da neurobiologia encontra um emprego no cotidiano: é porque existe um certo tipo de relações significantes entre Caroline e Gary, porque há um mundo comum entre eles e um contexto de casal, em que o DSM, o Prozac, a depressão tornaram-se elementos cotidianos de nossas vidas, que o cérebro é utilizado por Gary: é um recurso numa relação de força com sua mulher. $\mathrm{O}$ uso do cérebro é subordinado ao tipo de relação adotada pelo casal. Em outras palavras, o cérebro de Gary (como a psicoterapia de Caroline) 
é um elemento para agir dentro do todo relacional que forma o casal. O fracasso cerebral de Gary, sempre "em curso", é complementar ao sucesso psicoterápico de Caroline, para quem tudo está sempre under control. É, portanto, em relações significantes que podemos usar o cérebro. Aqui, o que está em jogo é: quem não tem e quem tem razão, em outras palavras, quem é responsável? Pois Gary quer ser responsável por tudo, salvo por ele mesmo. E para recordar a epígrafe: Gary tinha cada vez mais dificuldade de acreditar que seu problema não era neuroquímico, mas pessoal.

Mas o leitor deve evidentemente compreender que o seu problema é já, e desde o começo, um problema pessoal. Neste contexto, o seu uso do cérebro não lhe serve para nada.

Se seguíssemos Dumit (2004), poderíamos pensar que Gary usa seu selfobjetivo ou que essa é uma questão de biossocialidade para Thompson (1995). Mas é evidente que não há nada de objetivo na vida social de Gary (ele é, na melhor das hipóteses, personificado por sua neuroquímica, e de nenhuma forma objetivado por ela). A neuroquímica é uma referência para agir numa relação. No entanto, ela não ajuda a ganhar o jogo, assim como não ajuda Thompson a sair da depressão. Ao invés de falar da "formação do self-objetivo" e de acumular os Selfs (objetivo, subjetivo, social etc.), que mais produzem uma pilha do que mostram um agente social, deveríamos falar do contexto que permite empregar tal linguagem de justificativa da ação.

\section{ConteXtos InSTITUCIONAIS E PROFISSIONAIS QUE FAVORECEM O PROGRAMA FORTE}

No entanto, do lado do polo patológico, existe um problema real de estigmatização, particularmente nos Estados Unidos, e ele é institucional. A popularidade da abordagem naturalista encontra uma justificativa no tema da luta contra a estigmatização dos distúrbios mentais que o dualismo corpo-espírito e a distinção orgânico-funcional favoreciam. Um editorial recente de uma grande revista americana de psiquiatria destrincha o argumento: um dos problemas postos pela separação entre neurologia e psiquiatria é que ela "perpetua o dualismo corpo-espírito [...], fonte de estigmatização das doenças mentais que conduzem a uma falta de equidade na devolução dos tratamentos psiquiátricos em relação às outras condições médicas" (Yudofsky \& Hales, 2002: 1262).

A National Association for the Mentally Ill (NAMI), a mais importante associação americana de doentes mentais, defende uma concepção da doença mental como doença do cérebro. A NAMI se desenvolveu fortemente a partir do final dos 
anos 1970, quando a genética molecular começou suas pesquisas sobre as doenças psiquiátricas (Tobin, citado por Carson \& Rothstein, 1999). É certamente uma escolha de política psiquiátrica, mas o contexto do seguro-saúde nos Estados Unidos favorece essa escolha (uma verdadeira doença, a que atinge o corpo, é melhor reembolsada): o sistema institucional americano estimula, diferentemente do francês, uma concepção materialista. Há, portanto, uma justificativa prática para considerar essas patologias como problemas biológicos e médicos antes de tudo. A consequência das transformações da assessoria médica é que hoje os psiquiatras supermedicam os pacientes por precaução e por falta de poder fazer reembolsar psicoterapias custosas em tempo e em recursos humanos (Luhrmann, 2000).

Para os profissionais, é possível que essa neurologização da psiquiatria, sob as asas das neurociências, seja um meio de os psiquiatras reencontrarem um espaço social e uma identidade profissional no mundo dos psicoterapeutas e dos empreendedores do equilíbrio pessoal (renovações religiosas, grupos espiritualistas etc.) que drenam uma enorme clientela (inclusive entre os pacientes que se consultam em medicina geral e em psiquiatria), de um lado, e dos clínicos gerais que, por outro lado, dispõem atualmente de moléculas supermanuseáveis e praticam $80 \%$ das açôes psiquiátricas. Pois a psiquiatria, na qualidade de disciplina universitária, é capaz de responder do seu próprio jeito à demanda massiva e multiforme de saúde mental e de melhora do si. Ora, essa disciplina é trabalhada por uma tensão recorrente entre uma concepção do homem como ser corporal e uma concepção adversa do homem como ser de linguagem, tensão que resulta da especificidade das patologias de que ela trata: inúmeros sintomas correspondem às ideias que se faz de si-mesmo e do outro. Essa situação particular, que entrelaça a medicina, a moral e o social, faz com que a psiquiatria seja, ao mesmo tempo, uma medicina como outra qualquer e algo diferente da medicina. No contexto de explosão da demanda por saúde mental, essa situação fragiliza a legitimidade científica dessa profissão que é então tentada, para permanecer uma medicina como qualquer outra, pela fuga para os instrumentos, sem se dar conta da natureza dos fenômenos sobre os quais eles agem.

A psiquiatria deve, portanto, enquanto disciplina médica universitária, agir de modo que os ideais de seu público potencial (qualquer um entre nós, hoje em dia) sejam compatíveis com as normas científicas rigorosas. Com as neurociências, a psiquiatria entra na big science. Elas fornecem o estilo adequado que torna crível seu programa forte: têm teorias que correspondem fielmente às nossas representações do indivíduo (o cérebro é a versão materialista da totemização da personalidade - Ehrenberg, 2004), os instrumentos sofisticados e espetaculares (as técnicas de imageria cerebral), elas se apoiam sobre a ponta mais avançada da ciência (a 
neurobiologia molecular), permitindo a inclusão dos psicólogos e a aliança com a nebulosa espiritualista - o que multiplica as profissões, os atores e as clientelas suscetíveis de serem implicados. Pois é esse mesmo contexto que simultaneamente faz pesar sobre cada um a responsabilidade de ter de se construir por si mesmo como um todo autônomo e impele os cientistas a proporem soluçóes parcialmente ilusórias a esta preocupação maior das sociedades individualistas, a saber, a afirmação de que não somente nenhuma doença, mas, ainda, nenhuma situação social "problemática" deve ser abordada atualmente sem levar em consideração o sofrimento psíquico e sem visar à restauração da saúde mental. Compreendemos que a pesquisa da "Boa Saúde Mental" encoraja a extensão da pesquisa neurobiológica na direção dos comportamentos sociais e dos sentimentos morais. Mas é também porque o que está acontecendo nos laboratórios de neurociências levanta questôes que ultrapassam largamente as de uma sociologia da ciência.

\section{A ALIANÇA DO MITO INDIVIDUALISTA DA INTERIORIDADE E DA AUTORIDADE DA CIÊNCIA}

Há em biologia um grande número de generalizações, mas pouquíssima teoria, escreveu recentemente François Jacob (1999). O programa forte não substituiria uma teoria por uma generalização? Basta apostar nas ferramentas da biologia molecular e desenvolver métodos que abandonem o trabalho conceitual sobre a natureza dos fenômenos que pretendemos estudar e sobre aqueles sobre os quais esperamos agir de maneira prática?

Quando os biólogos (e não a biologia) afirmam provar que tudo vem do interior (inclusive o social), eles substituem a interioridade metafísica por uma interioridade biológica: a metafísica toma ares de questão científica. Que haja áreas cerebrais e redes neuronais ativadas não prova que a compreensão de outrem resida em um sentimento produzido pelo cérebro. Com efeito, "a compreensão empática não é um 'sentir'; ela é uma aptidão para participar de uma forma de vida” (Wright, citado por Bouveresse, 1982: 104) - entre a homossexualidade institucional da antiga Atenas e a orientação homossexual contemporânea não há nenhuma relação, a não ser a subjetividade mínima do ser vivo.

Os mecanismos biológicos são derivados da constituição social do homem que engloba a sua biologia. Também não se compreende, na verdade, por que uma das características naturais maiores da espécie humana consista em viver em sociedade, como se fosse somente uma questão de opção, como se as necessidades da espécie não fossem sociais. Suponhamos que se descubram, um dia, os mecanismos biológicos da culpa, da vergonha, da angústia. Será que não 
teríamos mais nenhuma razão (social e moral) para nos sentirmos culpados, envergonhados e angustiados? Esses sentimentos desempenham um papel lógico e antropológico tão indispensável para viver a vida humana quanto o corpo. Somos, portanto, equipados biologicamente para vivermos como seres sociais. Isso implica tomar como critério do mental não a interioridade, mas a significação (Descombes, citado por Ehrenberg \& Lovell, 2001), em outras palavras, a normatividade social: sem corpo não há ser humano, mas sem vida social, sem mundo comum, tampouco.

\section{REFERÊNCIAS BIBLIOGRÁFICAS}

Agid, Y. (2002). Réflexions à propos de l'avis "La neurochirurgie fonctionnelle d'affections psychiatriques sévères”. Les Cahiers du comité consultatif national d'éthique pour les sciences de la vie et de la santé, 32.

Albright, T. D.; Jessel, T. M.; Kandel, E. R. \& Posner, M. I. (2000). Neural science: a century of progress and the mysteries that remain. Cell, v. 100.

Andreasen, N. (2001). Brave new brain. Conquering mental illness in the era of the genome, London/New York: Oxford University Press.

Balint, M. (1960). Le médecin, son malade et la maladie. Paris: Payot.

Baron-Cohen, S. (2000). Is Asperger's Syndrome/High functioning autism necessarily a disability? Disponível em <http://www.geocities.com/CapitolHill/7138/lobby/ disability.htm>. Acessado em 07/09/2008.

Beaulieu, A. (2001). Voxels in the brain: neuroscience, informatics and changing notions of objectivity. Social Study of Science, v. 31, no 5, 635-680.

Berthoz, A. (2003). La décision. Paris: Odile Jacob.

Bouveresse, J. (1976/1987). Le mythe de l'intériorité. Expérience, signification et langage privé chez Wittgenstein. Paris: Minuit.

. (1982). L’animal cérémoniel. Em Wittgenstein, L. Remarques sur le Rameau d'or de Frazer (pp. 39-124). Paris: L'Âge d'homme.

Carson, R. A. \& Rothstein, M. A. (eds.). (1999). Behavioral genetics. The clash of culture and biology. Baltimore/London: John Hopkins University Press.

Castel, P.-H. (1998a). La querelle de l'hystérie. Paris: PUF.

Castel, P.-H. (1998b). Introduction à L'Interprétation du rêve de Freud. Paris: PUF.

Clerget-Darpoux, F. (2002). La folle course au gène de la folie. La Recherche, no 311, 4447.

Damásio, A. R. (1995). L'erreur de Descartes. Paris: Odile Jacob.

Descombes, V. (1995). La denrée mentale. Paris: Minuit. 
Detre, T. \& McDonald, M. (1997). Managed care and the future of psychiatry. Archives of General Psychiatry, v. 54, 201-204.

Dumit, J. (2004). Picturing personhood: brain scans and biomedical identity. New Jersey: Princeton University Press.

Edelman, G. M. (1992). Biologie de la conscience. Paris: Odile Jacob.

Ehrenberg, A. (1998). La fatigue d'être soi. Dépression et société. Paris: Odile Jacob.

. (2004). Les changements de la relation normal-pathologique. À propos de la souffrance psychique et de la santé mentale. Esprit, v. 304, no 5, 133-156.

Ehrenberg, A. \& Lovell, A. M. (orgs.). (2001). La maladie mentale en mutation. Paris: Odile Jacob.

Evans-Pritchard, E. E. (1937/1976). Witchcraft, oracles, and magic among the Azande. Oxford: Clarendon Press/Oxford University Press.

Forrester, J. (1984). Le langage aux origines de la psychanalyse. Paris: Gallimard.

Franzen, J. (2002). Les corrections. Paris: L'Olivier.

Goldstein, K. (1934/1983). La structure de l'organisme. Paris: Gallimard.

Harmon, A. (2004a). Answer, but no cure, for a social disorder that isolates many. New York Times, April 29, 2004. Disponível em <http://www.nytimes.com/2004/04/29/ national/29SYND.html? ex $=1398571200 \&$ en $=$ dad 83 cf87cb6f7 $17 \&$ ei $=$ 5007\&partner=USERLAND>. Acessado em 07/09/2008.

. (2004b). The disability movement turns to brain. New York Times, May 9, 2004. Disponível em <http://query.nytimes.com/gst/fullpage.html?sec=health\&res= 9C07E0D9143CF93AA35756C0A9629C8B63>. Acessado em 07/09/2008.

Hulbert, A. (2003). Raising America: experts, parents and a century of advice about children.

New York: Knopf.

Jacob, F. (1999). Qu'est-ce que la vie? Paris: Odile Jacob.

. (2000). La souris, la mouche et l'homme. Paris: Odile Jacob.

Kandel, E. R. (1999). Biology and the future of psychoanalysis: a new intellectual framework for psychiatry revisited. American Journal of Psychiatriy, 156, 505-524.

Korn, H. (org.). (2003). Neurosciences et maladies du système nerveux. Académie des sciences, Rapport sur la science et la technologie, 16.

Kremer, P. (2003). Fessée et insulte, ces "actes de violence qui ne se voient pas". Le Monde, 15 octobre 2003.

Lara, P. de (2004). L'homme rituel. Wittgenstein, sociologie, anthropologie. No prelo.

Leader, D. (2001). Freud et la question du genre. Paris: Payot.

Lemme, J. (2003). Les orphelins de Brooklyn. Paris: L'Olivier. 
Luhrmann, T. (2000). Of two minds. The growing disorder of American psychiatry. New York: Albert Knopf.

Martin, J. B. (2002). The integration of neurology, psychiatry and neuroscience in the 21 st Century. American Journal of Psychiatry, v. 159, no 5, 695-704.

Pearce, T. (2004). Too distracted to read this? We thought so. The Globe and Mail, May 15, 2004.

Plomin, R. \& McGuffin, P. (2003). Psychopathology in the postgenomic era. Annual Review of Psychology, no 54, 205-228.

Price, B. H.; Adams, R. D. \& Coyle, J. T. (2000). Neurology and psychiatry: closing the great divide. Neurology, v. 54, no 8, 8-14.

Rose, N. (1999). Governing the soul: the shaping of the private self. London: Free Associations Books.

Sacks, O. (1988). L’homme qui prenait as femme pour un chapeau. Paris: Le Seuil.

Servan-Schreiber, D. (2003). Guérir le stress, l'anxiété et la dépression sans médicaments ni psychanalyse. Paris: Laffont.

Shulman, R. G. (2001). Functionnal imaging studies: linking mind and basic neuroscience. American Journal of Psychiatry, v. 158, no 1, 11-20.

Thompson, T. (1995). The beast. A journey through depression. New York: Plume Book.

Tobin, A. (1999). Amazing Grace. Em Carson, R. A. \& Rothstein, M. A. (eds.). Behavioral genetics. The clash of culture and biology (pp. 1-11). Baltimore/London: John Hopkins University Press.

Yudofsky, S. T. \& Hales, R. E. (2002). Neuropsychiatry and the future of psychiatry and neurology. American Journal of Psychiatry, v. 159, 1261-1264.

\section{Notas}

1 Este artigo foi originalmente publicado sob o título de "Le sujet cérébral", na revista Esprit, no 309, 2004, pp. 130-155.

2 A este respeito ver os artigos de Gündel, M. H.; O’Connor, M.-F.; Littrell, L.; Fort, C. \& Lane, R. D. "Functional neuroanatomy of grief: an FMRI Study", e de Borg, J.; Andrée, B.; Soderstrom, H. \& Farde, L. "The serotonin system and spiritual experiences", os dois no American Journal of Psychiatry, novembro 2003 (o editorial do número é intitulado: "Toward a biochemistry of mind?"). Ver também "L'amour à l'épreuve des neurosciences", Le Journal du CNRS, fevereiro de 2004; "The science of love", The Economist, v. 14, no 20, fevereiro de 2004; Caspi, A.; McClay, J.; Moffitt, T. E.; Mill, J.; Martin, J.; Craig, I. W.; Taylor, A. \& Poulton, R., "Role of genotype in the cycle of violence in maltreated children", Science, v. 
297, 2 de agosto de 2003; "Neuromarketing: beyond branding", The Lancet Neurology, fevereiro de 2004. Sobre a decisão, vista muito generalizadamente, ver Berthoz (2003), que critica as teorias econômicas de ter negligenciado o cérebro.

3 Sobre o caso de depressão, ver Ehrenberg (1998).

4 Ver Ehrenberg (2004). Esse artigo e o presente estudo expóem cada um alguns aspectos das duas partes do ensaio em curso sobre o lugar das questóes mentais na sociedade da autonomia generalizada.

5 Ver Plomin e McGuffin (2003). Esses dois psiquiatras codirigiram um número especial do British Journal of Psychiatry sobre genética e psiquiatria em 1997.

6 Esse tipo de selfé particularmente empregado na antropologia médica foucaultiana. Ver Rose (1999) e Dumit (2004). Tudo se refere ao conceito de "biossocialidade" proposto em 1978 por Paul Rabinow (em Ehrenberg \& Lovell, 2001).

7 Apoiei-me sobre a análise de Pierre-Henri Castel (1998a), a qual revi para a análise aprofundada da constelação dos debates.

8 "Não deixemos então sugerir o que desejamos", escreve Castel (1998a: 82-83). É, conforme ele, "seu pressentimento [que] é a contribuição decisiva de Bernheim à visão moderna da subjetividade" (Castel, 1998a: 83).

9 Aqui, devemos distinguir entre a "neurologia da experiência viva" proposta por Oliver Sacks (1988), a saber, a atenção que ele depositou à psicologia dos pacientes neurológicos, e o "programa forte”, que visa eliminar toda psicologia. Sacks se inscreve na perspectiva holística do neurologista Kurt Goldstein ([1934] 1983).

${ }^{10}$ Entre diversos exemplos possíveis, ver Shulman (2001) ou Martin (2002), este último tendo participado da aplicação do Human Brain Project. Ver também Beaulieu (2001). Portanto, o que a imagética mostra são as atividades metabólicas locais que são, aliás, difíceis de interpretar. Ver igualmente Agid (2002). Agid dirige o Instituto Federativo de Pesquisa em Neurociências localizado no La Salpêtrière. Esse instituto reagrupa os serviços de psiquiatria e neurologia, assim como inúmeros laboratórios de pesquisa. Ele dispõe de uma plataforma técnica muito sofisticada em imagética cerebral.

${ }^{11}$ As aproximações mentalistas, quer sejam materialistas ou espiritualistas, "substituem uma experiência por uma relação", escreveu Vincent Descombes (1995: 276-277).

12 Ver igualmente, entre outros, Price, Adams e Coyle (2000) e Yudofsky e Hales (2002).

${ }^{13}$ Ver Clerget-Darpoux (2002), que é presidente da Société Internationale de Génétique Épidémiologique). Allan Tobin (1999), diretor do Brain Research Institute da UCLA, mostra a mesma coisa.

14 “Autisme, vers la fin des querelles?". La Recherche, no 373, março 2004, pp. 38-45.

15 É paradoxal constatar que, por um lado, não cessamos de falar de maus-tratos, dito de outra forma, de relaçóes, ao ponto de que a surra torna-se em si mesma uma violência (Kremer, 
2003) e, por outro lado, uma total indiferença à relação patogênica. Ver também o projeto de lei posto no Parlamento europeu visando interditar a surra na União Europeia pelo motivo de que ela constitui atentado aos direitos humanos.

${ }^{16}$ Michael Balint (1960) tem sublinhado há mais de cinquenta anos que o maior problema da medicina geral é a incompreensão dos verdadeiros problemas do paciente.

${ }^{17}$ Sobre a diferença entre a subjetividade do autômato e da autonomia, ver Descombes (1995: 217-223).

${ }^{18}$ Ver a entrevista de M. Ricard, intérprete do Dalaï-Lama, Le Monde, 13 de outubro de 2003.

19 Substituo "suas noções místicas" pelas "nossas noções científicas".

${ }^{20} \mathrm{O}$ retardo mental profundo e o autismo de Kanner. O diagnóstico data igualmente de 1943.

${ }^{21}$ Ver Harmon (2004a, 2004b).

${ }^{22}$ Ver Pearce (2004). O National Institute for Mental Health produziu um guia para os learning disabilities.

${ }^{23}$ Ver o romance de Jonathan Lemme (2003), cujo personagem principal é atento à síndrome de Tourrete. Aqui, o cérebro conta, ele faz pressão sobre os pensamentos dos personagens, que reagem com tapas intempestivos, com grosserias ou fluxos verbais. 